\title{
First retrospective studies with etiological confirmation of porcine transmissible gastroenteritis virus infection in Argentina
}

\author{
Pablo Enrique Piñeyro ${ }^{1 *} \mathbb{D}$, Maria Inez Lozada ${ }^{2}$, Laura Valeria Alarcón ${ }^{3}$, Ramon Sanguinetti ${ }^{4}$, \\ Javier Alejandro Cappuccio ${ }^{5}$, Estefanía Marisol Pérez ${ }^{2}$, Fabio Vannucci ${ }^{6}$, Alberto Armocida², Darin Michael Madson? \\ Carlos Juan Perfumo ${ }^{2}$ and Maria Alejandra Quiroga ${ }^{2}$
}

\begin{abstract}
Background: In 2014, a notification of porcine transmissible gastroenteritis virus (TGEV) was made by the National Services of Animal Health of Argentina (SENASA) to the World Organization of Animal Health (OIE). The notification was based on a serological diagnosis in a small farm with a morbidity rate of $2.3 \%$ without enteric clinical signs. In order to determine if TGEV was circulating before the official report, a retrospective study on cases of neonatal diarrhea was performed. The selection criteria was a sudden increase in mortality in 1- to 21-day-old piglets with watery diarrhea that did not respond to antibiotics. Based on these criteria, three clinical cases were identified during 2010-2015.

Results: All animals that were evaluated presented histological lesions consistent with enteric viral infection. The feces and ultrathin sections of intestine that were evaluated by electron microscopy confirmed the presence of round particles of approximately $80 \mathrm{~nm}$ in size and characterized by finely granular electrodense nucleoids consistent with complete particles of coronavirus. The presence of the TGEV antigen was confirmed by monoclonal specific immunohistochemistry, and final confirmation of a metabolically-active virus was performed by in situ hybridization to detect a TGE mRNA encoding spike protein. All sections evaluated in this case were negative for PEDV and rotavirus A.

Conclusions: This is the first case series describing neonatal mortality with etiological confirmation of TGEV in Argentina. The clinical diagnosis of TGEV infections in endemic regions is challenging due to the epidemiological distribution and coinfection with other enteric pathogens that mask the clinical presentation.
\end{abstract}

Keywords: Porcine transmissible gastroenteritis virus, Diarrhea, Mortality, Piglets

\section{Background}

There are five coronaviruses (CoVs) known to infect swine, and the clinical disease is mainly associated with neonatal diarrhea, but respiratory and neurological signs have also been reported [1-4]. Porcine transmissible gastroenteritis virus (TGEV) and porcine epidemic diarrhea virus (PEDV) belong to the Coronaviridae family, Coronavirinae subfamily, and genus Alphacoronavirus [5]. A new coronavirus genetically distinct from TGEV

\footnotetext{
* Correspondence: pablop@iastate.edu; pablop@iastae.edu

${ }^{1}$ Veterinary Diagnostic Laboratory, 1655 Veterinary Medicine, lowa State

University, 1850 Christensen Drive, Ames, IA 50011, USA

Full list of author information is available at the end of the article
}

and PEDV, porcine deltacoronavirus (PDCoV) (genus Deltacoronavirus), has recently been associated with enteric disease in pigs [6]. Enteric porcine coronaviruses including TGEV, PEDV and PDCoV are characterized by acute diarrhea and anorexia with rapid dissemination in naïve populations. The severities of clinical diarrhea, vomiting, and anorexia can vary based on the age of the affected pigs $[7,8]$. Without adequate passive lactogenic immunity, the mortality rate in neonatal piglets can reach up to $100 \%$ [1, 9-11]. Etiological diagnosis relies mainly on molecular tools like PCR and serology, as the clinical signs and enteric lesions associated with TGEV and PEDV are indistinguishable $[8,12,13]$.

(C) The Author(s). 2018 Open Access This article is distributed under the terms of the Creative Commons Attribution 4.0 International License (http://creativecommons.org/licenses/by/4.0/), which permits unrestricted use, distribution, and 
The epidemiology of TGEV is rather complex, and infection in neonates can arise from multiple sources. In addition to swine, it has be documented that cats, dogs, and foxes can host TGEV [14]. The virus can be shed in feces for approximately 18 months, and milk shedding from infected sows can result in vertical transmission. Historically, TGEV infection has followed a seasonal pattern, becoming more prevalent during winter months perhaps due to increased viral survival in colder temperatures and with less exposure to sunlight. TGEV is susceptible to most commercial disinfectants, but resistant to digestive bile and stable at pH 3 [1]. Only one TGEV genotype has been described, however differences in pathogenicity among strains has been reported in field outbreaks, although not confirmed by an experimental study [12].

Infection with TGEV has two different clinical presentations: epidemic and endemic. In epidemics, TGEV enters a naïve herd and all pig categories are affected, particularly piglets that are $1-2$ weeks old. The duration of the clinical presentation is short, approximately 3 weeks, and in small, farrow-to-finish herd, the infection can be self-limiting $[1,14]$. Endemic disease scenarios, those occurring after the epidemic phase, are observed in farms with incomplete AIAO management or in breeding farms that have a continuous flow of naïve gilts. In breeding herds, the varying levels of humoral and lactogenic immunity lowers piglet mortality, but may lengthen the course of the disease [1].

Since the first description provided in the United States [15], TGEV infections have been reported all over the world. In South America, it has been reported in Colombia [16], Venezuela [17], Bolivia, and is currently seen in Brazil [18]. In Argentina, an episode of high pre-weaning mortality related to Isospora suis infection alone or in association with an unknown enteric virus was reported in 1998 [19]. Further studies using negative stain electron microscopy demonstrate the presence of viral particles consistent with coronavirus in feces of pre-weaning diarrheic (34.4\%) and post-weaning (10\%) piglets [20]. A retrospective histopathological study performed on cases of neonatal diarrhea at our laboratory during 2013 showed that $29 \%$ of neonatal diarrhea cases had lesions consistent with viral enteritis [21]. In 2014, a notification of TGEV infection was reported by the National Services of Animal Health of Argentina (SENASA) to the World Organization of Animal Health (OIE). It was detected by serology in a small farm with an apparent morbidity rate of $2.3 \%$ without clinical signs [22]. This is an unusual presentation of TGEV infection and might be related to passed infection or interspecies transmission [1].

In order to clarify the situation prior to the first official report of TGEV infection in Argentina, a retrospective study was performed on cases suspected of TGEV-like disease recorded at the Laboratory of Special Veterinary
Pathology at the College of Veterinary Sciences, La Plata University. Benchmarking analyses of epidemiological behavior and clinical histories were the criteria for herd selection. Etiological diagnosis was confirmed by electron microscopy (EM), immunohistochemistry (IHC), and in situ hybridization (ISH-RNA) of archived paraffin blocks.

\section{Results \\ Clinical, pathological and etiological findings \\ Case 1}

Thirteen 1- to 7-day-old piglets with body weights ranging from 1 to $1.5 \mathrm{~kg}$ were submitted for pathological investigation. Pigs with clinical diarrhea were dirty, wet, had stained perinea, and showed moderate dehydration characterized by sunken eyes and diffusely pale mucosa. Their small intestinal walls were thin with unremarkable mesenteric lymphatic vessels, and were distended by gas or occasionally contained yellow watery digesta with a $\mathrm{pH}$ of 5-6 (Fig. 1a). Their stomachs were empty or contained floccules of undigested milk. No other macroscopic findings were observed. The histopathological evaluation showed a shortening of intestinal villi with a crypt-villous ratio of 1:2 (Fig. 1b), that villi were fused and lined by vacuolated cuboidal or attenuated epithelium, and that the lamina propria was expanded by moderate edema. Microscopic lesions were limited to the jejunum and ileum. Immunohistochemistry and ISH-RNA against TGEV showed strong staining in the epithelium of sections that presented minimal epithelial villous changes (Fig. 1c, d). Conversely, sections with the most severe epithelial damages were IHC negative. All sections evaluated in this case were negative for PEDV and rotavirus.

\section{Case 2}

A gross evaluation of five piglets between 2 and 3 days old showed marked dehydration, wet and stool-stained perinea, and poor body conditions $(1.15 \mathrm{~kg}$ average body weight) (Fig. 2a). The small intestine contained abundant yellow-watery diarrhea with a $\mathrm{pH}$ of 5-6 in two pigs and alkaline $\mathrm{pH}$ in three pigs (Fig. 2b). A histopathology examination of multiple sections of jejunum and ileum showed mild to moderate villous shortening and fusion (Fig. 2c). The villous enterocytes showed a marked cytoplasmic vacuolization (Fig. $2 \mathrm{~d}$ ). The lamina propria was minimally infiltrated by lymphocytes and plasma cells, and was expanded by edema. The superficial villous enterocytes in the ileum showed strong hybridization signals characterized by active-replicating TGEV (Fig. 2e). No microscopic lesions were seen in the sections of colon. All sections evaluated in this case were negative for PEDV and Rotavirus A. In the ultrathin sections, rounded particles measuring approximately $80 \mathrm{~nm}$ in diameter were located in the cytoplasm of the intestinal epithelial cells. The particles were characterized by finely 


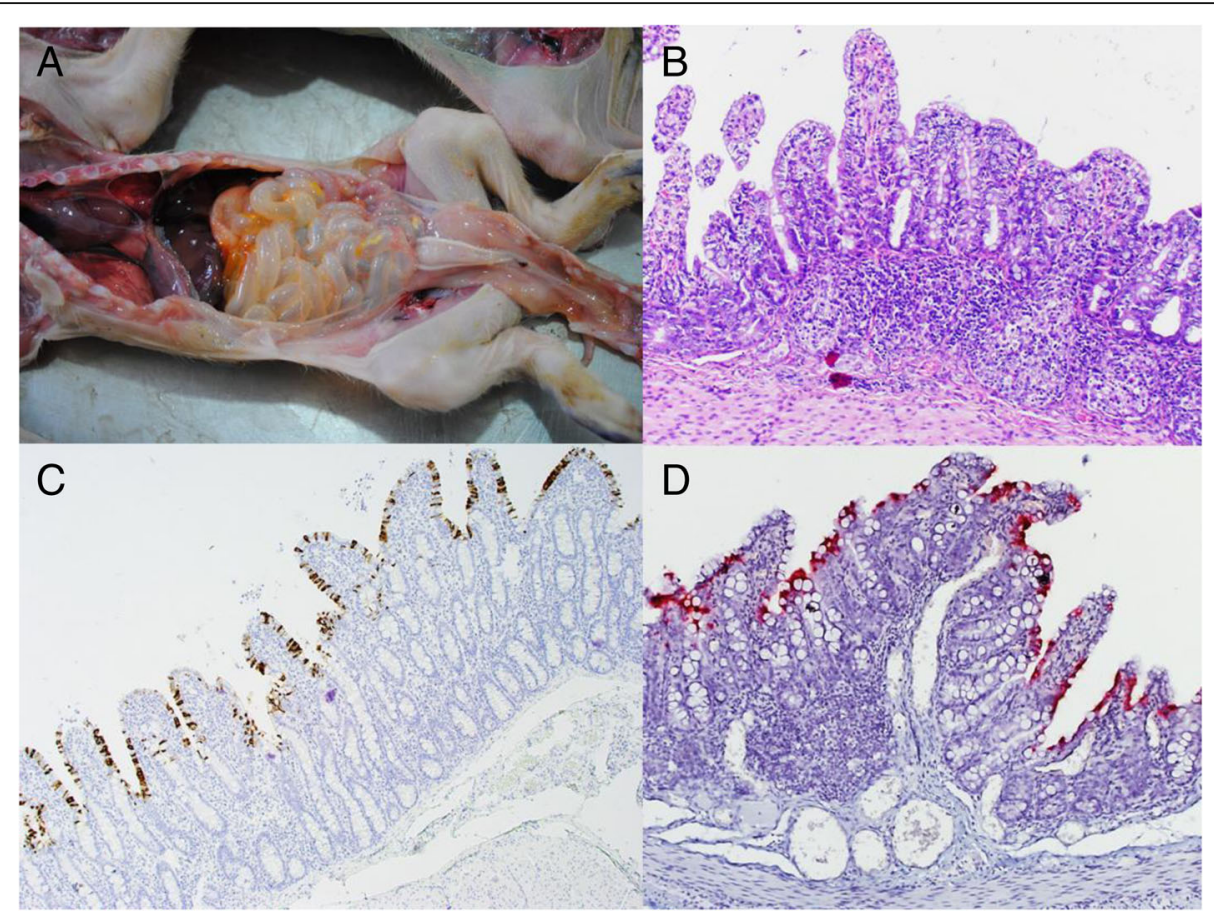

Fig. 1 Gross and histological findings in neonatal piglets affected with TGEV detected in case 1. a shows thin small intestinal walls and loops distended by gas containing scant yellow watery digesta. $\mathbf{b}$ shows histological changes characterized by villous shortening, fusion and moderate submucosal edema. $\mathbf{c}$ and $\mathbf{d}$ present viral detection by IHC and ISH-RNA respectively. Note the severity of viral distribution affecting the entire length of the villi

granular electrodense nucleoids with electron lucent centers compatible with complete particles of coronavirus (Fig. 2f).

\section{Case 3}

Three neonatal piglets that died naturally presented with fecal stained perinea and were markedly dehydrated. The stomachs were empty, the small intestinal wall was thin/translucent, and scant yellow watery contents were sometimes apparent. The histopathology examination of the jejunum and ileum showed moderate villous fusion and shortening, and the villi were lined by low-cuboidal to flattened/attenuated epithelium (Fig. 3a). The lamina propria was infiltrated by numerous lymphocytes and plasma cells, was expanded by edema, and exhibited lymphangiectasia (Fig. 3b). The TGEV antigen was detected by IHC in multiple sections of the jejunum and ileum (Fig. 3c). No significant lesions were observed in the section of colon. All sections evaluated in this case were negative for PEDV and Rotavirus A.

\section{Discussion}

The epidemiological and clinical presentations of outbreaks of neonatal mortality associated with enteritis and the detection of TGEV started in the gestation units. Both gilts and sows showed anorexia, diarrhea, and vomiting before enteric signs were observed in neonatal piglets. However, the prevalence of clinical signs in the breeding stock was low and no mortality was reported. When TGEV enters in a naïve herds, an epizootic form characterized by a $100 \%$ mortality of pre-weaning piglets due to diarrhea and dehydration is normally observed [ 1 , 14]. Although in the present study, the farms had a high prevalence of diarrhea in suckling pigs, only farms A and $C$ showed almost $100 \%$ neonatal mortality, while in farm B had approximately $20 \%$ neonatal mortality. The clinical presentation and epidemiological pattern observed in farm B resembled the TGE endemic form. Although no other etiological diagnosis was confirmed, the low mortality associated with TGEV that was observed in farm B might be the result of previous exposure to PRCV. PRCV infection can confer cross-protection against TGEV, reducing the enteric clinical signs and pre-weaning mortality [12]. Therefore, herds concomitantly infected with PRCV and TGEV develop less severe clinical signs, making the clinical differentiation from other enteric infections such as rotavirus or $E$. coli infections more challenging $[1,14]$. Another potential reason for the low mortality rate due to TGE infection that was observed in farm B could be the intermittent viral exposure of the breeding stock that provided partial immunity to the neonatal piglets [14]. In all herds in this study, it was suspected that the virus entered the farms through the subclinically infected replacement animals 


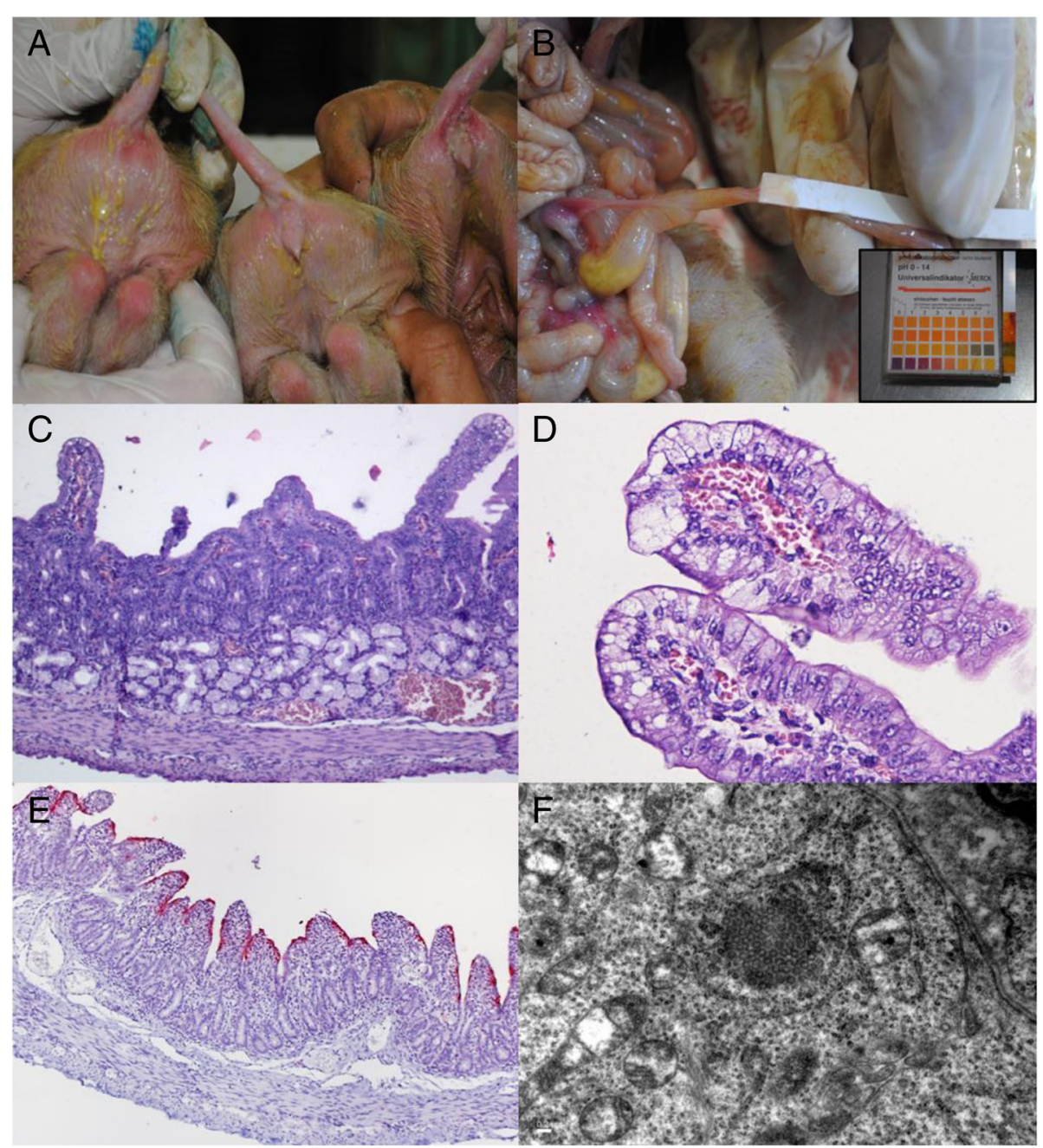

Fig. 2 Gross and histological changes and viral detection in neonatal piglets affected with TGEV in case 2. Piglets presented with stool-stained perineum (a). Intestinal loops have thin walled, distended by gas and contain abundant yellow-watery diarrhea with 5-6 pH (b). Multiple sections of small intestine showed villous atrophy, blunting and fusion (c) with occasional cytoplasmic vacuoles (d). The presence of TGE mRNA confirmed in positive ISH-RNA enterocytes through multiple section of jejunum and ileum (e). f shows intracytoplasmic particles characterized by finely granular electrodense nucleoids with electron lucent centers compatible coronavirus

that were not quarantined, or that the herds were exposed to the virus due to the proximity of a farm to a slaughterhouse (as seen in farm B).

Although the pre-weaning mortality rate in farm $\mathrm{B}$ was lower than that in farm A and C, the pre-weaning mortality was higher in this farm than the mortality rate seen in similar production systems due to other enteric causes such us I suis [19, 23], C. perfringes type A [24], or C. difficile [25]. According to a previous study, the pre-weaning mortality due to diarrhea should not exceed 20\% [26]. Usually, in porcine CoVs infections, the course of the clinical disease is short and normally does not exceed 3-4 weeks [14] due to the establishment of a rapid herd immunity, as early as one week post-infection. However, in farm B the clinical presentation persisted for approximately 2 months. Potential reinfection due to poor husbandry and incomplete AIAO management are just few potential causes of viral persistence in the environment that can predispose reinfection of the farrowing units.

In clinically affected litters, most of the pigs are dirty, wet, and dehydrated, with diminished body weights. Diarrhea is watery, yellowish, and with an acidic smell from the presence of undigested milk [23]. The mortality rate is inversely correlated with the age of the piglets, reaching $100 \%$ in $2-7$ day-old piglets. This predisposition is due to the slow replacement rate of villus epithelial cells (around 10 days) in neonatal piglets compared with the replacement rate of 3-week-old piglets (around 2-4 days) [14]. In this study, mortality varied from 20 to $100 \%$.

The jejunum and ileum are the target segments of the small intestine for virus multiplication. However, TGEV infection is segmental, so multiple segments should be 

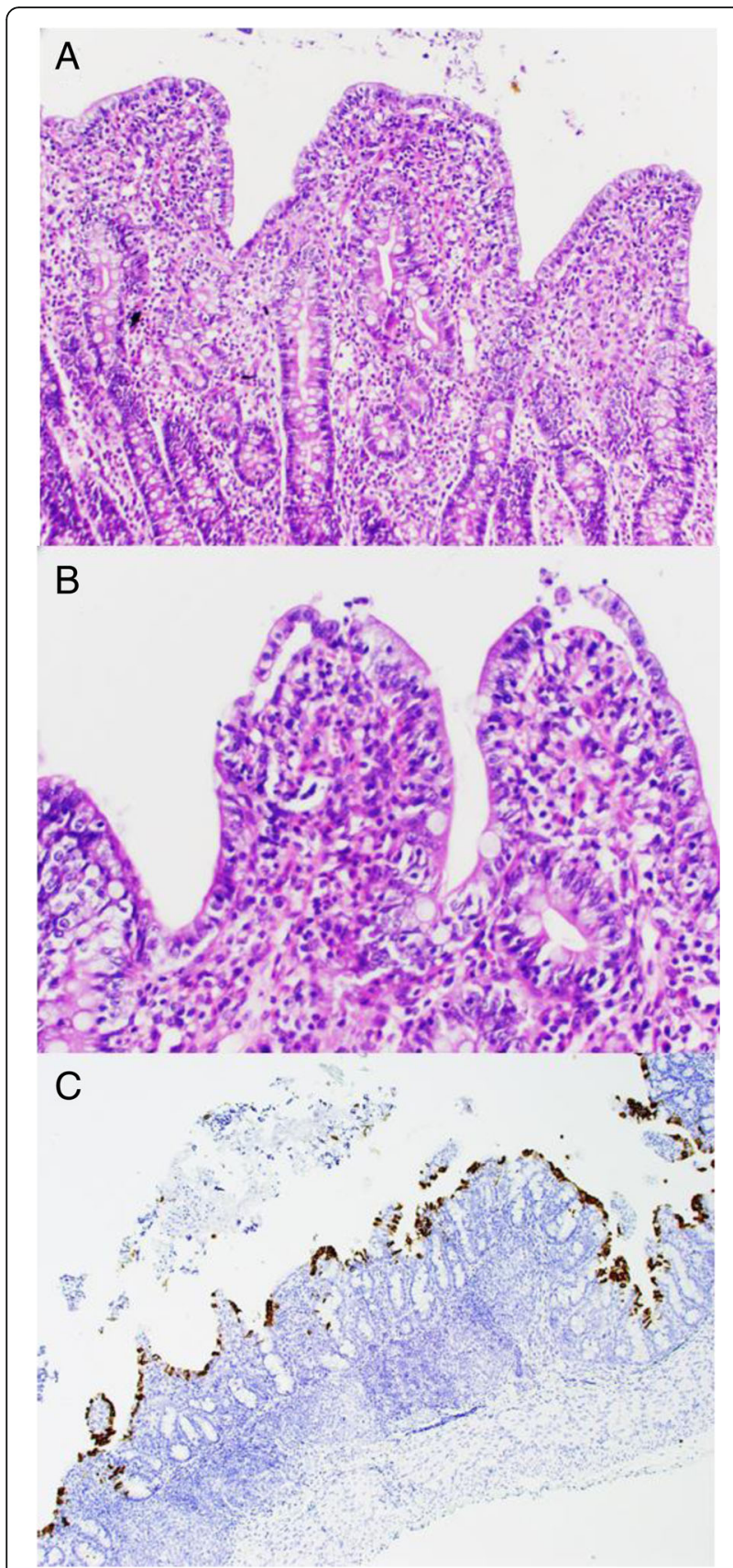

Fig. 3 Histological changes and TGE-IHC detection small intestine in neonatal piglets affected with TGEV in case 3. a shows moderate villous atrophy and villi lined by low-cuboidal attenuated epithelium. There is also infiltration of the lamina propria by lymphocytes and plasma cells and minimal edema (b). Note the strong immunoreactivity against TGEV in superficial enterocitos (c)

included for histopathology or etiological diagnoses in situ such as IHC or ISH-RNA. Due to the retrospective nature of this study, fixed tissue was used to confirm the presence of TGEV and the morphological changes consistent with viral infection in the intestinal mucosa. It is important to highlight that although TGEV was detected by different means in each farm, due to the segmental nature of the lesions and viral distribution, viral ARN or viral antigen was not detected in all of the intestinal segments that were evaluated. In piglets that are less than 2 weeks old, the reduction of villus length and the fusion of jejunum and proximal ileum are the main histological changes [27]. The normal villous/crypt length ratio is 7:1, however, after $24-48 \mathrm{~h}$ post-infection, the villous/ crypt ratio can be reduced to $2: 1$ or 1:1 [27]. Since TGEV replicates in mature absorptive epithelial cells [28], a false negative diagnosis can be observed by IHC or ISH in specimens that display villous shortening. Few absorptive vacuolated cells are seen normally in the intestine, however, during TGEV infection, they are found in great numbers with a cuboidal shape [27]. In endemic TGEV infection, histopathological diagnosis is more difficult because only $25 \%$ of pigs display typical TGE lesions. In addition, immunofluorescence tests and IHC often fail in endemic farms due to a low number of enterocytes in the TGEV-infected because of partial protection conferred by colostral antibodies [23, 29]. Different diagnostic techniques have been used to detect TGEV infection such as IHC, ISH, electron microscopy, and immunoelectron microscopy and PCR [13]; however, histopathology remains the most useful tool for screening diagnosis [18]. In this study, although all cases were selected using clinical features and epidemiological information, the histological evaluation consistently showed lesions compatible with viral infection.

\section{Conclusions}

The application of IHC and ISH-RNA on archived paraffin blocks from cases of neonatal diarrhea with high morbidity and mortality allowed retrospective identification of TGEV infection. Diagnosis of TGEV infection in endemic regions, such as in Argentina, is complicated due to the epidemiological distribution and clinical signs that might be masked with other enteric infections. Further studies are necessary to determine the true prevalence of this pathogen and the correlation with neonatal enteric cases observed in confined production systems.

\section{Methods}

\section{Case selection and clinical history}

Case selection was based on the clinical history reported by the farm managers and referring veterinarians. The selection criteria was a sudden increase in mortality that included, significant increment of more than 2 SD from average pre-weaning mortality and last for a period of a week. In addition reported mortality should be associated with the presence of watery diarrhea in 1- to 21-day-old piglets that did not respond to antibiotics. First screening of cases was done by histopathological evaluation, and only cases presenting features of viral 
enteritis with no other detected pathogen were included. Based on these criteria, three clinical cases were identified from 2010 to 2015.

\section{Case 1}

A 170-sow farrow-to-finishing herd located in Buenos Aires served as the first case. The farm produced its own replacement breeding stock, however, two months before the outbreak, gilts were introduced from a breeding company. The parity of the breeding stock was distributed as $40 \%$ gilts while the rest of the reproductive stock parity varied from 2 to 6 . On September 2011, approximately $10 \%$ of the pregnant sows presented acute vomiting while $30 \%$ of the pregnant sows presented acute diarrhea. During the period when the sows showed gastro-enteric clinical signs, 2- to 4-day-old piglets presented vomiting (75$80 \%$ ) and diarrhea $(90 \%)$, and the mortality rate of suckling pigs reached $90 \%$. The course of the disease in both breeder stock and piglets lasted for approximately three weeks.

\section{Case 2}

Case 2 involved a one-site herd of 350 sows with its own replacement gilts and the following parity distribution: $20 \%$ gilts, $40 \%$ parity $1-2$, and $27.3 \%$ distributed amongst parity $3-5$. Boars were purchased from a breeding company and were incorporated into the reproductive herd without quarantine. The farm was located within a few miles of a swine slaughterhouse in Buenos Aires. In February 2012, the pregnant sows showed anorexia (14-30\%) and diarrhea (1\%) associated with heat returns and abortions (3.3\%). In the farrowing houses, approximately $100 \%$ of the lactating sows presented with anorexia. Pre-weaning mortality associated with the presence of diarrhea varied from $16.5 \%$ at the beginning of the outbreak to $27.9 \% 3$ to 4 weeks after the initial clinical signs. An anatomopathological evaluation showed that $93.6 \%$ of the total pre-weaning mortality was due to diarrhea.

\section{Case 3}

A one-site herd of 400 sows was the subject of Case 3. In July 2013, two boars were located close to the gestation unit. A week later, gestation sows showed anorexia (16.8\%) and diarrhea (5.3\%). Thereafter, in the gilts, diarrhea was evident in the nursery $(3-7 \%)$ and fattener (5-23\%). Two-day-old piglets showed watery diarrhea $(100 \%)$ with a mortality rate of $95 \%$. Affected piglets died from severe dehydration within two days of the onset of clinical signs. The course of the disease lasted approximately two months with an overall pre-weaning mortality of $50 \%$ during that period.

\section{Pathological studies}

At the onset of the outbreak, clinically affected suckling pigs were submitted for postmortem examination. Tissue samples from different organs, including multiple segments of small intestine (duodenum, jejunum, and ileum) and large intestine, were fixed in 10\% buffered formalin, processed for routine histopathologic examination, and stained with hematoxylin and eosin.

\section{Etiological diagnosis in tissues and feces by immunohistochemistry, in situ hybridization, and electron microscopy}

Immunohistochemestry IHC was carried-out briefly to differentiate TGEV [30] from PEDV [31]. Monoclonal antibodies against TGEV (OSU: \#.14E3-3C) and PEDV (OSU 6C8) at dilutions of 1:8000 were used. Antigen retrieval was performed with humid heat and revealed with peroxidase (Novocastra ${ }^{\mathrm{a}}$, Leica Biosystems, IL, USA). To rule out other potential viral enteritis, Rotavirus A was evaluated in all sections by IHC [32]. Rotavirus IHC was performed using a monoclonal antibody against Rotavirus A (Santa Cruz: sc-101363) at a 1:2000 dilution. Antigen retrieval was performed with Epitope Retrieval Solution 2 for $20 \mathrm{~min}$, as programmed on Leica Bond III, and revealed with PowerVision Poly-HRP anti-Mouse (Leica PV 6113). All samples were tested in duplicate and sections were controlled appropriately for TGEV, PEDV and Rotavirus A with positive and negative controls (Additional file 1: Figure S1).

In situ hybridization ISH-RNA was developed through the RNAScope platform (Advanced Cell Diagnostics, Inc., CA), targeting the specific reverse complementary nucleotide sequence of the TGE viral mRNA (716-1859 region of spike gene, GenBank: KC609371.1). Therefore, positive hybridization signals represent a metabolically-active virus characterized by the TGE mRNA encoding spike protein. Unstained paraffin tissue sections were processed as previously described [33]. Briefly, tissues were deparaffinized and treated with hydrogen peroxide at room temperature for $10 \mathrm{~min}$. The slides were hybridized using a hybridization buffer, and sequence amplifiers were added. The red colorimetric staining detected the TGE hybridization signal, and counterstaining occurred with hematoxylin.

Representative sections of small intestine were fixed in $2.5 \%$ glutaraldehyde and $2 \%$ paraformaldehyde in $0.1 \mathrm{M}$, $\mathrm{pH}$ 7.4 phosphate buffer (PBS) and post-fixed in $1 \%$ osmium tetroxide in PBS. After dehydration in an alcohol series, the fragments were embedded in epoxy resin, Quetol 812 (Nisshin EM Co., Ltd., Tokyo). Ultrathin sections were cut, double-stained with uranyl acetate-lead citrate, and observed under a JEM-1200EX (JEOL Co. Ltd., Tokyo). 


\section{Additional file}

Additional file 1: Figure S1. Panel of pathogens used as control for detection of TGEV by immunohistochemistry. Row one include immunostaining of TGEV clinical cases against TGEV, PEDV, and rotavirus specific antibodies. A moderate to severe immunostaining is observe only reacting against TGEV. In row two include positive controls for each pathogen detected by immunohistochemistry. Row three present section tested negative by PCR for TGEV, PEDV, and Rotavirus that were used as negative control of the immunohistochemistry techniques. (PPTX $3545 \mathrm{~kb}$ )

\section{Abbreviations}

AIAO: All in all out; CoVs: Coronaviruses; EM: Electron microscopy; HRP: Horseradish peroxidase; IHC: Immunohistochemistry; ISH: In situ hybridization; mRNA: Messenger ribonucleic acid; OlE: World Organization of Animal health; PBS: Phosphate buffer saline; PCR: Polymerase chain reaction; PDCoV: Porcine deltacoronavirus; PEDV: Porcine epidemic diarrhea virus; SENASA: Argentina services of animal health; TGE: Porcine transmissible gastroenteritis; TGEV: Porcine transmissible gastroenteritis virus

\section{Availability of data and materials}

The authors declare that all the data supporting the findings of this report is available in the article.

\section{Authors' contributions}

PEP, CJP, MAQ performed histological examination, data analysis and conclusion and were the major contributors in writing the manuscript; DMM, Performed IHC; FV, Performed ISH; MIL, RS, JAC, EMP, AA, LVA field data collection and case identification. All authors read and approved the final manuscript.

\section{Ethics approval and consent to participate}

Not applicable.

\section{Consent for publication}

Not applicable.

\section{Competing interests}

The authors declare that they have no competing interests.

\section{Publisher's Note}

Springer Nature remains neutral with regard to jurisdictional claims in published maps and institutional affiliations.

\section{Author details}

Veterinary Diagnostic Laboratory, 1655 Veterinary Medicine, lowa State University, 1850 Christensen Drive, Ames, IA 50011, USA. ² Laboratorio de Patología Especial Veterinaria FCV-UNLP, Calle 60 y 118 S/N (1900), La Plata, Buenos Aires, Argentina. ${ }^{3}$ HIPRA Argentina, Saenz Peña R. Pte. Av 1110, Capital Federal, Argentina. ${ }^{4}$ DILACOT-SENASA, Av A Fleming 1653, Martinez, Buenos Aires, Argentina. ${ }^{5}$ EEA Marcos Juaréz, INTA, CONICET, Ruta 12 km. 3 (2580), Marcos Juárez, Córdoba, Argentina. ${ }^{6}$ Veterinary Diagnostic Laboratory, University of Minnesota, 1333 Gortner Ave, St Paul, MN, USA.

Received: 28 June 2017 Accepted: 16 September 2018 Published online: 24 September 2018

\section{References}

1. Saif LJ, Pensaert MB, Sestak K, Yeo SG, Jung K. Coronaviruses. In: Zimmerman JJ, Karriker LA, Ramirez A, Schwartz KJ, Stevenson GW, editors. Diseases of Swine. 10th ed. Ames: Willey; 2012. p. 501-23.

2. Wang $L$, Byrum B, Zhang Y. New variant of porcine epidemic diarrhea virus, United States, 2014. Emerg Infect Dis. 2014;20(5):917-9.

3. Quiroga MA, Cappuccio J, Pineyro P, Basso W, More G, Kienast M, Schonfeld S, Cancer $J L$, Arauz S, Pintos ME, et al. Hemagglutinating encephalomyelitis coronavirus infection in pigs, Argentina. Emerg Infect Dis. 2008;14(3):484-6.

4. Laude $\mathrm{H}$, Van Reeth $\mathrm{K}$, Pensaert M. Porcine respiratory coronavirus: molecular features and virus-host interactions. Vet Res. 1993;24(2):125-50.
5. González JM, Gomez-Puertas P, Cavanagh D, Gorbalenya AE, Enjuanes L. A comparative sequence analysis to revise the current taxonomy of the family Coronaviridae. Arch Virol. 2003;148(11):2207-35.

6. Chen Q, Gauger P, Stafne M, Thomas J, Arruda P, Burrough E, Madson D, Brodie J, Magstadt D, Derscheid R, et al. Pathogenicity and pathogenesis of a United States porcine deltacoronavirus cell culture isolate in 5-day-old neonatal piglets. Virology. 2015;482:51-9.

7. McCluskey BJ, Haley C, Rovira A, Main R, Zhang Y, Barder S. Retrospective testing and case series study of porcine delta coronavirus in U.S. swine herds. Prev Vet Med. 2016;123:185-91.

8. Song D, Moon H, Kang B. Porcine epidemic diarrhea: a review of current epidemiology and available vaccines. Clin Exp Vaccin Res. 2015;4(2):166-76.

9. Stevenson GW, Hoang H, Schwartz KJ, Burrough ER, Sun D, Madson D, Cooper VL, Pillatzki A, Gauger P, Schmitt BJ, et al. Emergence of porcine epidemic diarrhea virus in the United States: clinical signs, lesions, and viral genomic sequences. J Vet Diagn Investig. 2013;25(5):649-54.

10. Jung K, Saif L. Porcine epidemic diarrhea virus infection: etiology, epidemiology, pathogenesis and immunoprophylaxis. Vet J. 2015;204(2):134-43.

11. Poonsuk K, Giménez-Lirola LG, Zhang J, Arruda P, Chen Q, Correa da Silva Carrion L, Magtoto R, Pineyro P, Sarmento L, Wang C, et al. Does circulating antibody play a role in the protection of piglets against porcine epidemic diarrhea virus? PLoS One. 2016;11(4):e0153041.

12. Kim L, Hayes J, Lewis P, Parwani AV, Chang KO, Saif LJ. Molecular characterization and pathogenesis of transmissible gastroenteritis coronavirus (TGEV) and porcine respiratory coronavirus (PRCV) field isolates co-circulating in a swine herd. Arch Virol. 2000;145(6):1133-47.

13. Woods RD. Development of PCR-based techniques to identify porcine transmissible gastroenteritis coronavirus isolates. Can J Vet Res. 1997;61(3): 167-72.

14. Sestak K, Saif LJ. Porcine coronavirus. In: Trends in emerging viral infections of swine. Edited by Morilla A, Yoon K-J, Zimmerman JJ. Ames: lowa State Press; 2002:321-30.

15. Doyle LP, Hutchings LM. A transmissible gastroenteritis in pigs. J Am Vet Med Assoc. 1946:108:257-9.

16. Piñeros R, Mogollón Galvis JD. Coronavirus en porcinos: importancia y presentación del virus de la diarrea epidémica porcina (PEDV) en Colombia. Rev Med Vet. 2015;29:73-89.

17. Marin C, Rolo M, López N, Álvarez L, Castaños H, Sifontes S. Detección de focos de gastroenteritis transmisible en Venezuela. Vet Trop. 1985;10:35-42.

18. Martins AMCRPF, Bersano JG, Ogata R, Amante G, Nastari BDB, Catroxo MHB. Diagnosis to detect porcine transmissible gastroenteritis virus (TGEV) by optical and transmission electron microscopy techniques. Int J Morphol. 2013;31:706-15

19. Perfumo C, Venturini L, Sanguinetti $H$, Aguirre J, Armocida A, Petruccelli M, Moredo F. Infección por Isospora suis sola o asociada a virus entéricos como causa de alta morbimortalidad en lechones lactantes. Revta Med Vet. 1998;79:264-8.

20. Aguirre II, Petruccelli MA, Armocida AD, Moredo FS, Risso M, Venturini L, Idiart JR, Perfumo CJ. Diarrea en lechones lactantes y posdestete de cuatro criaderos intensivos de la provincia de Buenos Aires, Argentina: identificación e índice de detección de partículas virales en materia fecal por microscopía electrónica. Analecta Vet. 2000;20(2):16-21.

21. Chavez F, Pérez E, Barrales H, Zignago F, Lozada M, Quiroga M, Machuca M, Cappuccio J, Perfumo C. Análisis de los cuadros entéricos en cerdos remitidos al Laboratorio de Patología Especial Veterinaria (2013). In Proceeding of: Memorias XII Congreso Nacional de Producción Porcina: $12-$ 15 agosto 2014. Mardel Plata; 2014, 2014. p. 178.

22. Carné LÁ. Transmissible gastroenteritis, Argentina. In: OIE, editor. Servicio Nacional de Sanidad y Calidad Agroalimentaria (SENASA), Ministerio de Agricultura, Ganadería y Pesca: World Organization of Animal health; 2014.

23. Dewey CE, Carman S, Hazlett M, Dreumel TV, Smart NE. Endemic transmissible gastroenteritis: difficulty in diagnosis and attempted confirmation using a transmission trial. J Swine Health Prod. 1999;7(2):73-8.

24. Sanz MG, Venturini L, Assis RA, Uzal F, Risso MA, Idiart JR, Perfumo CJ. Fibrinonecrotic enteritis of piglets in a commercial farm: a postmortem study of the prevalence and the role of lesion associated agents Isospora suis and Clostridium perfringens. Pesqui Vet Bras. 2007;27:297-300.

25. Cappuccio JA, Quiroga MA, Moredo FA, Canigia LF, Machuca M, Capponi O, Bianchini A, Zielinski G, Sarradell J, Ibar M, et al. Neonatal piglets mesocolon edema and colitis due to Clostridium difficile infection: prevalence, clinical disease and pathological studies. Braz J Vet Pathol. 2009;2(1):35-40. 
26. Sanz M, Sernia C, Viale G, Bustos L, Sanguinetti H, Risso M, Venturini L, Idiart J, Perfumo C. Why Should Piglets Dead at the Pre-weaning Period be Postmortem Examined and Statistically Analysed at Weekly Intervals? In Proceeding of: 32nd Annual Meeting American Association of Swine Practitioners: February 24-27, 2001. Nashville; 2001. p. 69-74.

27. Hooper $\mathrm{BE}$, Haelterman EO. Lesions of the gastrointestinal tract of pigs infected with transmissible gastroenteritis. Can J Comp Med. 1969;33(1):29-36.

28. Moeser AJ, Blikslager AT. Mechanisms of porcine diarrheal disease. J Am Vet Med Assoc. 2007;231(1):56-67.

29. Pritchard GC. Transmissible gastroenteritis in endemically infected breeding herds of pigs in East Anglia, 1981-85. Vet Rec. 1987;120(10):226-30.

30. Shoup DI, Swayne DE, Jackwood DJ, Saif LJ. Immunohistochemistry of transmissible gastroenteritis virus antigens in fixed paraffin-embedded tissues. J Vet Diagn Investig. 1996;8(2):161-7.

31. Kim O, Chae C, Kweon C-H. Monoclonal antibody-based

Immunohistochemical detection of porcine epidemic diarrhea virus antigen in formalin-fixed, paraffin-embedded intestinal tissues. J Vet Diagn Investig. 1999;11(5):458-62.

32. Magar R, Larochelle R. Immunohistochemical detection of porcine rotavirus using Immunogold silver staining (IGSS). J Vet Diagn Investig. 1992;4(1):3-7.

33. Wang F, Flanagan J, Su N, Wang L-C, Bui S, Nielson A, Wu X, Vo H-T, Ma X-J, Luo Y. RNAscope: a novel in situ RNA analysis platform for formalin-fixed, paraffin-embedded tissues. J Mol Diagn. 2012;14(1):22-9.

Ready to submit your research? Choose BMC and benefit from:

- fast, convenient online submission

- thorough peer review by experienced researchers in your field

- rapid publication on acceptance

- support for research data, including large and complex data types

- gold Open Access which fosters wider collaboration and increased citations

- maximum visibility for your research: over $100 \mathrm{M}$ website views per year

At $\mathrm{BMC}$, research is always in progress.

Learn more biomedcentral.com/submissions 